\title{
Editorial
}

\section{Depression, Suicidal Ideation, and Resilience among Rural Drought-Affected Farmers: Methodological Issues}

Following a natural disaster, such as drought, mental health issues may crop up as a result of several stressors. Chief among them are job/business loss, financial loss, resource crunch, and possible migration due to loss of opportunities. ${ }^{[1]}$ Given these fallouts, it is likely that stress mediates the link between drought and psychological morbidity such as depression and anxiety.

Quantitative studies that examine the links between drought and depression/anxiety are comparatively fewer from low-and middle-income countries. For this reason, the study on depression, suicidal ideation (SI) and resilience among drought-affected rural farmers published in this issue of the journal ${ }^{[2]}$ is a welcome effort. A better understanding of the relationship between drought and psychiatric morbidity would, doubtless, help drought preparedness, inform preventive and management strategies, and identify at-risk subgroups for targeted prevention. However, there are some methodological considerations to be kept in mind while interpreting the study findings.

First, the authors mention that simple random sampling was done to select their sample. The use of a probability sampling technique such as the simple random sampling necessitates the elaboration of a sampling frame (practically operationalized as a list of all potential participants in the setting of interest). Subsequently, the lottery method or random number tables can be used to pick subjects for inclusion. Essentially, all participants have an equal chance of getting selected. ${ }^{[3]}$ In the index study, the authors have selected one village "at random," and all farmers from that village were included in the study. This cannot be called a simple random sampling but instead, is a convenience sampling. In studies like these, it would be better to recruit participants from multiple villages as ground level realities may vary from village to village. Moreover, it is conceivable that shared experiences within the same locality could have impacted responses.

Second, the authors have used a widely quoted measure of resilience, the Connor-Davidson Resilience Scale, a 25-item self-report scale that seeks to quantify resilience, ${ }^{[4]}$ a protective psychological construct. Being a self-report instrument, the authors have used a translated version. However, the paper is silent on the procedure used for translation as well as the psychometric properties of the translated version. These are key omissions that impact judgment on the validity of study findings.
Third, and perhaps, most importantly, are some core methodological considerations. For instance, there is no information whether preexisting psychiatric morbidity was accounted for among the study participants. This would obviously have implications in ascribing the observed morbidity to the impact of drought. Furthermore, as both anxiety and depression are likely to be common psychological sequelae of disasters, it is unclear why the authors choose to focus on depression alone using the Patient Health Questionnaire-9 (PHQ-9). The validity of PHQ-9 for detecting cases of anxiety and depression has been questioned. ${ }^{[5]}$ A better alternative would have been to use screening instruments designed to pick up general psychological distress such as the General Health Questionnaire, which incidentally is validated in the local language ${ }^{[6]}$ and combine it with the use of a diagnostic interview such as the Mini International Neuropsychiatric Interview (MINI) ${ }^{[7]}$ as a two-step assessment. If one is applying only the selected modules of MINI, this approach would not take much time but would have significantly added value to the study.

For SI, the authors used the ninth item of PHQ-9 which enquires about passive thoughts of death or self-harm in the preceding 2 weeks. Evidence suggests that this approach is insufficient in assessing SI and a negative response on PHQ-9 cannot be equated with nil suicidalty and needs further probing. ${ }^{[8]}$ As the authors do not state anything about the latter, it must be assumed that additional probes were not used in case of a negative response to the question on SI. An alternative would have been to utilize the widely used Columbia Suicide Severity Rating Scale, ${ }^{[9]}$ a simple and more valid measure.

Many of the factors studied for their association with depression such as type of farming, years spent in farming may have limited relevance from a therapeutic perspective. Here, the authors, perhaps, missed a trick by not studying modifiable factors such as coping skills and social support which could be key mediators in the link between drought and psychological distress. ${ }^{[1]}$ The authors should also have conducted a multivariate analysis if their objective was to identify factors associated with depression as doing a univariate analysis alone does not address issues of multicollinearity between covariates and would not identify independent predictive factors.

In summary, the authors address an important area, but the choice of instruments, their application as 
well as data treatment issues affect the validity and clinical utility of findings. Researchers must take these methodological considerations into account while planning similar studies in the future.

Vikas Menon

Department of Psychiatry, Jawaharlal Institute of Post Graduate Medical Education and Research, Puducherry, India

Address for correspondence: Dr. Vikas Menon, Department of Psychiatry, Jawaharlal Institute of Post Graduate Medical Education and Research, Puducherry - 605 006, India.

E-mail: drvmenon@gmail.com

\section{REFERENCES}

1. Vins H, Bell J, Saha S, Hess JJ. The mental health outcomes of drought: A systematic review and causal process diagram. Int $\mathrm{J}$ Environ Res Public Health 2015;12:13251-75.

2. Viswanathan DJ, Veerakumar AM, Hemalatha K. Depression, suicidal ideation, and resilience among rural drought-affected farmers: Methodological issues. J Neurosci Rural Pract 2019;10:179-80.

3. Eaton WW, Kessler LG. Epidemiologic Field Methods in Psychiatry: The NIMH Epidemiologic Catchment Area Program. Orlando: Academic Press; 2012.

4. Connor KM, Davidson JR. Development of a new resilience scale: The Connor-Davidson resilience scale (CD-RISC). Depress Anxiety 2003;18:76-82.

5. Eack SM, Greeno CG, Lee BJ. Limitations of the patient health questionnaire in identifying anxiety and depression: Many cases are undetected. Res Soc Work Pract 2006;16:625-31.

6. Kuruvilla A, Pothen M, Philip K, Braganza D, Joseph A, Jacob KS, et al. The validation of the Tamil version of the
12 item general health questionnaire. Indian $\mathrm{J}$ Psychiatry 1999;41:217-21.

7. Sheehan DV, Lecrubier Y, Sheehan KH, Amorim P, Janavs J, Weiller E, et al. The mini-international neuropsychiatric interview (M.I.N.I.): The development and validation of a structured diagnostic psychiatric interview for DSM-IV and ICD-10. J Clin Psychiatry 1998;59 Suppl 20:22-33.

8. Na PJ, Yaramala SR, Kim JA, Kim H, Goes FS, Zandi PP, et al. The PHQ-9 item 9 based screening for suicide risk: A validation study of the patient health questionnaire (PHQ)-9 item 9 with the Columbia suicide severity rating scale (C-SSRS). J Affect Disord 2018;232:34-40.

9. Posner K, Brown GK, Stanley B, Brent DA, Yershova KV, Oquendo MA, et al. The Columbia-suicide severity rating scale: Initial validity and internal consistency findings from three multisite studies with adolescents and adults. Am J Psychiatry 2011;168:1266-77.

This is an open access journal, and articles are distributed under the terms of the Creative Commons Attribution-NonCommercial-ShareAlike 4.0 License, which allows others to remix, tweak, and build upon the work non-commercially, as long as appropriate credit is given and the new creations are licensed under the identical terms.

\begin{tabular}{|c|c|}
\hline \multicolumn{2}{|c|}{ Access this article online } \\
\hline Quick Response Code: & \\
\hline 口值咜回 & $\begin{array}{l}\text { Website: } \\
\text { www.ruralneuropractice.com }\end{array}$ \\
\hline 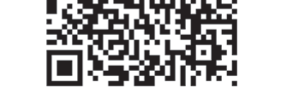 & $\begin{array}{l}\text { DOI: } \\
\text { 10.4103/jnrp.jnrp_341_18 }\end{array}$ \\
\hline
\end{tabular}

How to cite this article: Menon V. Depression, suicidal ideation, and resilience among rural drought-affected farmers: Methodological issues. J Neurosci Rural Pract 2019;10:176-7. 